\title{
B chromosomes: from cytogenetics to systems biology
}

\author{
${\text { Guilherme T. } \text { Valente }^{1} \cdot \text { Rafael T. Nakajima }}^{2}$ - Bruno E. A. Fantinatti ${ }^{2}$. \\ Diego F. Marques ${ }^{2} \cdot$ Rodrigo O. Almeida $^{1} \cdot$ Rafael P. Simões $^{1} \cdot$ Cesar Martins $^{2}$
}

Received: 1 July 2016 /Revised: 10 August 2016/Accepted: 15 August 2016 /Published online: 24 August 2016

(C) Springer-Verlag Berlin Heidelberg 2016

\begin{abstract}
Though hundreds to thousands of reports have described the distribution of B chromosomes among diverse eukaryote groups, a comprehensive theory of their biological role has not yet clearly emerged. B chromosomes are classically understood as a sea of repetitive DNA sequences that are poor in genes and are maintained by a parasitic-drive mechanism during cell division. Recent developments in highthroughput DNA/RNA analyses have increased the resolution of B chromosome biology beyond those of classical and molecular cytogenetic methods; B chromosomes contain many transcriptionally active sequences, including genes, and can modulate the activity of autosomal genes. Furthermore, the most recent knowledge obtained from omics analyses, which is associated with a systemic view, has demonstrated that B chromosomes can influence cell biology in a complex way, possibly favoring their own maintenance and perpetuation.
\end{abstract}

Keywords Cytogenomics · Supernumerary chromosomes · Genomics · Evolution

This article is related to the 21st International Chromosome Conference (Foz do Iguaçu, Brazil, July 10-13, 2016).

Cesar Martins

cmartins@ibb.unesp.br

1 Department of Bioprocess and Biotechnology, Agronomic Science School, UNESP - Sao Paulo State University, Botucatu, SP 18610-307, Brazil

2 Department of Morphology, Institute of Biosciences, UNESP - Sao Paulo State University, Sao Paulo, Botucatu 18618-689, Brazil

\section{The legacy of B chromosomes}

B chromosomes (Bs) are enigmatic accessory elements to the regular chromosome set (A) and, since their discovery at the beginning of the twentieth century (Wilson 1907), Bs have ranked among the main topics of chromosome biology. The importance of $\mathrm{B}$ chromosomes is illustrated by the series of conferences on $\mathrm{B}$ chromosomes that have been organized during the last three decades (1st, 2nd and 3rd B chromosome Conferences in 1993, 2004, and 2014, respectively). B chromosome science has advanced from classical (conducted during most of the twentieth century) and molecular cytogenetics (conducted from 1990 to 2010) to genomics and bioinformatics approaches (conducted during the last few years). Recent advances in next-generation sequencing (NGS) technologies and high-throughput molecular biology protocols have led to the B chromosome becoming the subject of massive data analysis, thus enabling an investigation of structural and function$\mathrm{al}$ issues at a level that was previously never considered possible. Here, B chromosome history will be reviewed with an emphasis on recent advances resulting from high scale DNA and RNA analyses and their contribution to the construction of new concepts regarding B chromosomes.

Bs are regularly found in some but not all individuals within a population and are considered dispensable. In 2005, the number of species harboring B chromosomes was approximately 2000 species, including animals, plants, and fungi (for a review, see Camacho 2005). Bs can occur in up to $14 \%$ of karyotyped orthopteran insect species and in as many as $10-15 \%$ of cytogenetically known flowering plants (Jones 1995). Such frequencies might have increased in the last decade as Bs have been described for new taxonomic groups. Most B chromosomes are rich in heterochromatin, gene poor, and composed of repeated DNA sequences. These characteristics seem to support the modest or absent effects of Bs on 
their hosts. Consequently, the presence of Bs is not associated with any phenotype in most species.

Although classically considered non-functional, both beneficial and harmful effects of Bs have been described. One of the most harmful effects of Bs on fitness is the energy cost of $\mathrm{B}$ maintenance during the cell cycle and their potential interference with the proper assortment of As during meiosis (Jones and Reed 1982). B chromosome effects are more frequently associated with vigor and fertility (Camacho et al. 2000). One of the classical influences of Bs is their role in meiosis, during which they increase chiasma frequency and recombination (as reviewed in Jones 1995; Camacho 2005; Burt and Trivers 2006). Other effects of Bs have been observed in cichlid fishes (Yoshida et al. 2011), in which Bs are likely to play a role in sex determination, and in the fungus Nectria haematococca, in which Bs confer antibiotic resistance and pathogenicity (Coleman et al. 2009). The high occurrence of Bs without clear benefits for most host species appears to be related to their high transmission rate due to drive mechanisms that cause non-Mendelian segregation at meiosis or post-meiotic events (Jones 1991); these mechanisms increase the probability of Bs being retained in the host genome, according to a parasitic model (Camacho 2005). Although the parasitic model for B chromosomes appears plausible and has been observed worldwide, the molecular mechanisms that regulate $\mathrm{B}$ chromosome maintenance and segregation during the cell cycle remains enigmatic.

\section{The application of cytogenetics and genomics to $B$ chromosome analysis}

Cytogenetic science was born with the first analysis of chromosomal behavior during cell division, which was carried out at the end of the nineteenth century and at the beginning of the twentieth century (for a review, see Martins et al. 2011). During the first half of the twentieth century, animal chromosomes were viewed in tissue sections, yielding imprecise and incorrect information. In the second half of the twentieth century, high-quality chromosomes were obtained from cell suspensions and cell cultures and were subjected to new methods of chromosome staining and banding. Such new methods enabled rapid progress in the cytogenetic field. After 1980, due to advances in molecular biology, cytogenetics was used in combination with molecular biology techniques, thus allowing significant advances in understanding genomes through chromosome studies. After the first hybridizations of DNA/RNA molecules to the nucleus and chromosomes (Pardue and Gall 1969; Gall and Pardue 1969), several studies used radioactively labeled repetitive DNAs (rRNA genes and satellite DNAs), and the latter experiments used fluorescent in situ hybridization (FISH) techniques (Pinkel et al. 1986) that allowed the simultaneous hybridization of multiple
gene/DNA sequences on chromosomes. Modified plasmids (BACs - bacterial artificial chromosomes, cosmids, and fosmids, among others) were used to construct libraries containing large $(30-300 \mathrm{~kb})$ genomic segments and probes representing the DNA pool of partial or whole chromosomes; such techniques enabled researchers to refine chromosome analysis methods, thus allowing the development of chromosome painting and multicolor hybridization during the 1990s.

The availability of several completely sequenced eukaryotic genomes in the last decade opened new avenues for cytogenetics, thus opening further prospects for the physical chromosomal mapping of genes and comparative analyses. The advent of new genome sequencing technologies in the 2000s suggested that cytogenetics would become obsolete and that molecular/genomic tools would solve most biological questions, including those related to chromosomes. However, although most recent technological advances in genomics have proved to be of great importance for chromosome biology, significant genome data can be acquired from fundamental cytogenetic studies involving the identification of chromosome number and morphology as well as the advanced molecular and bioinformatics approaches that are applied in cytogenetics. Furthermore, the integration between genomic sequencing and physical chromosome mapping is very useful for classical genomic projects, in which the mapping of contigs/scaffolds onto chromosomes was considered a "golden path" to better understanding genomes. In this way, both genomics and cytogenetics have advanced as genomic data have been integrated with chromosome analysis, allowing the emergence of cytogenomics as a new field of biological research.

Advances in various forms of the large-scale analysis of DNA, RNA, and proteins, and in the study of chromatin modification have reduced the time, cost, and difficulties involved in the study of complex genomes, thus allowing the development of audacious structural and functional projects, such as "ENCODE" (https://www.encodeproject.org/), "Genome 10 K” (genome10k.soe.ucsc.edu/), "i5K" (arthropodgenomes. org/wiki/i5K), "1000 Genomes" (http://www.1000 genomes. org), and "The Cancer Genome Atlas" (http://cancergenome. nih.gov), among others. The exploration of genomic data from the perspective of chromosome biology has allowed the use of higher resolution approaches for understanding the basis of chromosomal changes during evolution. Currently, the field of cytogenetics is synergistic with genomics, and the integration of structural and functional genomics with cytogenetics has the potential to clarify the molecular mechanisms governing the origin and fate of chromosomal rearrangements during evolution.

Classical and molecular cytogenetic approaches have been extensively applied to the study of B chromosomes in an attempt to answer questions regarding their origin and evolution. Although important findings have been made, such 
techniques present limited resolution at the molecular level. The recent development of large-scale genomic analysis has also advanced the field of chromosome biology, including the study of B chromosomes. Millions of sequences can be generated for several genome samples of interest, which can then be used to identify chromosomal variations. The ordinary mapping of sample reads to a reference genome allows the identification of duplicated genomic/chromosomal regions based on a quantitative study of the sequences generated (Fig. 1). This is particularly useful in studies of polymorphism in large chromosomes, such as B or sex chromosomes. The genomic regions of specific chromosomes can be identified, annotated, and subjected to deep analysis using quantitative PCR and FISH mapping (Fig. 1). Furthermore, the generation of large RNA datasets and their analysis using powerful bioinformatics tools also contribute to studies of B chromosomes, thus providing a global view of cell physiology (Fig. 2).

Next-generation sequencing enables the use of large-scale analysis to explore B chromosome biology in plants, animals, and fungi. Flow-sorted isolated B chromosomes of rye (Secale cereale) have been analyzed using 454 Roche NGS sequencing (Martis et al. 2012); the findings showed that rye B chromosomes are mostly derived from the autosomes $3 R$ and $7 R$, with the subsequent accumulation of sequences from the other autosomes and organelle genomes. Large-scale genomic analysis of the cichlid fish Astatotilapia latifasciata (Valente et al. 2014) based on the Illumina NGS of microdissected B chromosome and whole DNA from B+ (presence of one or two B chromosomes) and $\mathrm{B}-$ (absence of $\mathrm{B}$ chromosomes) animal samples showed that the $\mathrm{B}$ chromosome contains thousands of sequences that have been duplicated from almost all
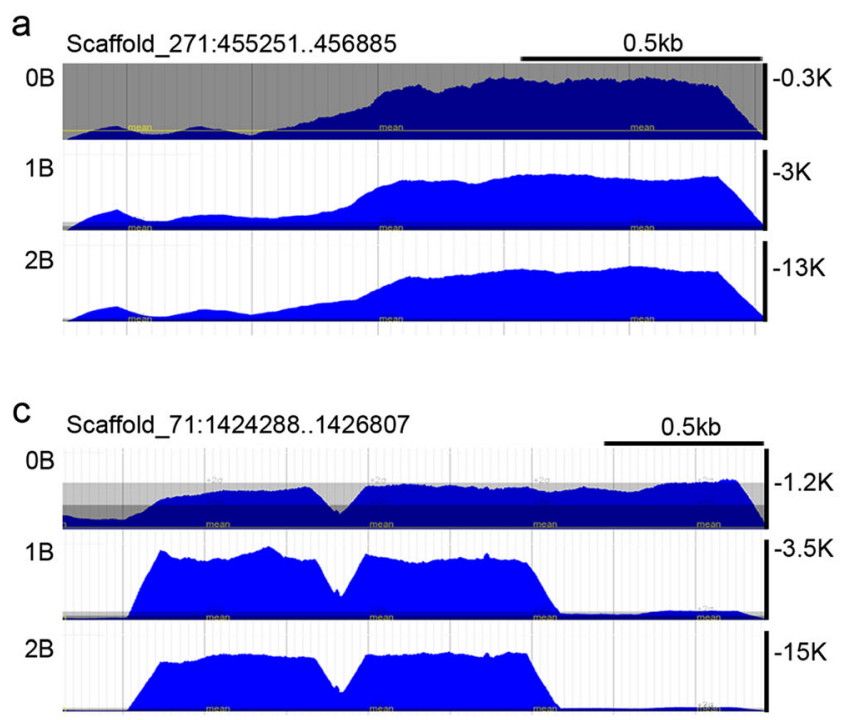

Fig. 1 Sequencing coverage of three representative scaffold regions (ac) for the $O B, 1 B$, and $2 B$ genomes of the cichlid fish Astatotilapia latifasciata aligned against the reference genome of the cichlid Metriaclima zebra. The higher read coverage for samples $1 B$ and $2 B$ provide evidence for rounds of segmented duplications that increased chromosomes of this species. Although most genes on B chromosomes are fragmented, some are largely intact. Wholegenome shotgun (WGS) sequencing of the fungal wheat pathogen Mycosphaerella graminicola (Goodwin et al. 2011) showed that the chromosome dispensome set (accessory chromosomes) contains some genes and repetitive sequences from most or all of the core chromosomes, with additional unique genes of unknown origin. Although the chromosome dispensome of M. graminicola is not maintained by meiotic drive as are the classical $\mathrm{B}$ chromosomes, it can be lost with no visible effect on the fungus (Wittenberg et al. 2009). NGS technology enables the large-scale analysis of genomic content, which was not possible in classical and molecular cytogenetics, and the identification of a larger number of genes and DNA elements that are related to specific karyotype variations. This information changes the classical view of B chromosomes as being gene-poor, suggesting that Bs can exert effective action over cell biology.

\section{Genes and functional sequences on B chromosomes}

Repetitive DNA classes, including mobile elements and satellite DNAs, are enriched in B chromosomes, as extensively described in many studies (for a review, see Camacho 2005; Burt and Trivers 2006). The identification of protein coding genes and transcriptionally active sequences has advanced over the last decade, considerably altering our view of the molecular structure of Bs. The first discovery of proteincoding genes in Bs of the fungus $N$. haematococca (Miao et al. 1991) was followed by a growing number of reports

b
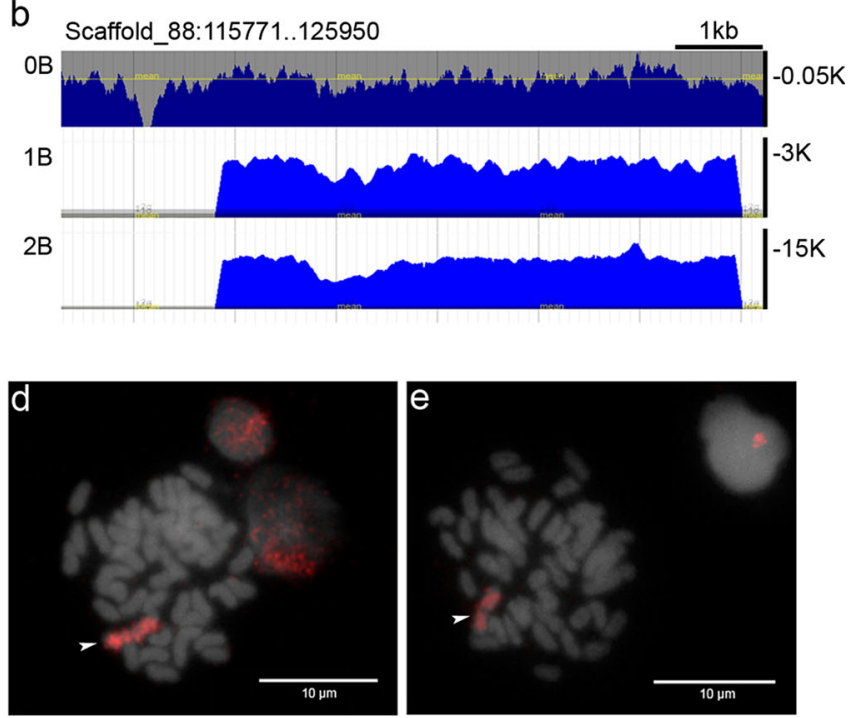

the copy number for $\mathrm{B}+$ sequences. The read coverage is indicated at the left of the figures. The higher sequencing coverage detected under genomic analysis is corroborated by FISH-mapping (d, e). d, e Represent FISH-mapping of genomic regions a, b, respectively. Arrowheads indicate the $\mathrm{B}$ chromosomes in $\mathbf{d}$ and $\mathbf{e}$ 
Fig. 2 Global metrics of coexpression network, representative miRNA/coding genes regulatory network, and gene ontology (GO) analysis for $\mathrm{B}-$ and $\mathrm{B}+$ samples of $A$. latifasciata. a Degree distribution for $\mathrm{B}+$ and $\mathrm{B}-\mathrm{co}$-expression networks. The power law is clearly observed in both situations and indicate reliable biological networks; $\mathbf{b}$ Box-plot of all node degrees calculated for $\mathrm{B}+$ and $\mathrm{B}-$ networks. The $\mathrm{B}+$ network is larger than $\mathrm{B}^{-}$and contains more diverse connections; c Venn diagram representing the number of transcripts in both networks. The number of GO-annotated transcripts is also shown; $\mathbf{d}$ partial network showing the regulation between up-regulated miRNAs (red nodes) and targeted genes (black nodes); e hierarchical network of the molecular functions of $\mathrm{B}+$ genes. Red circles indicate molecular functions terms with high-scored values, and gray circles represent statistically unsupported nodes a
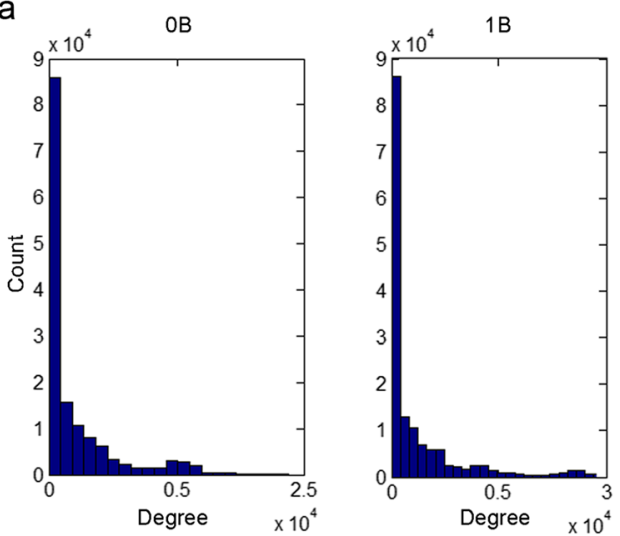

C

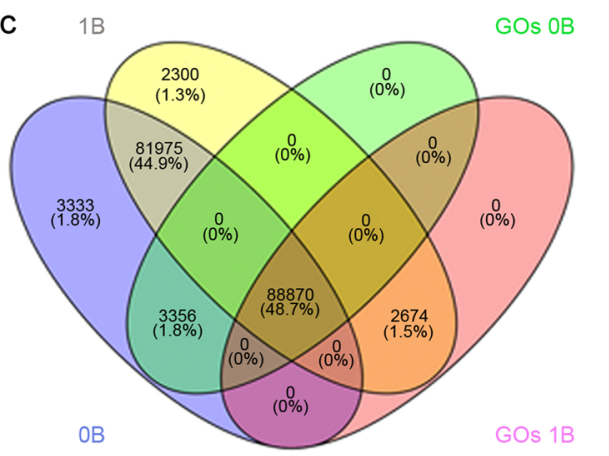

b

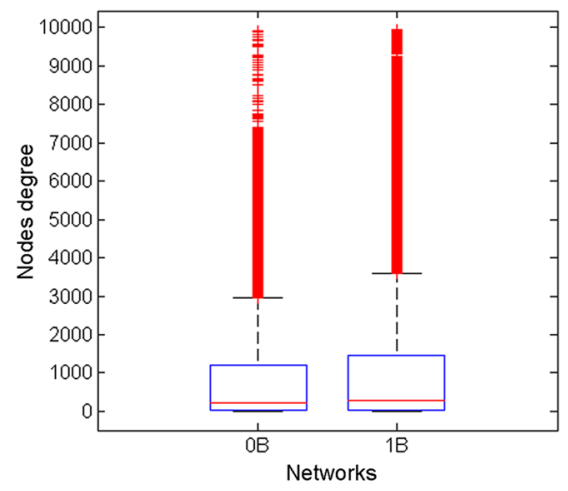

d

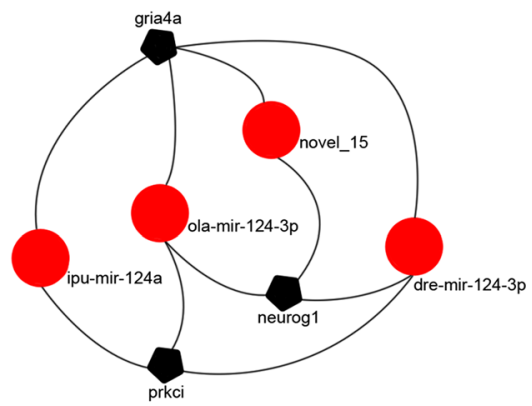

e

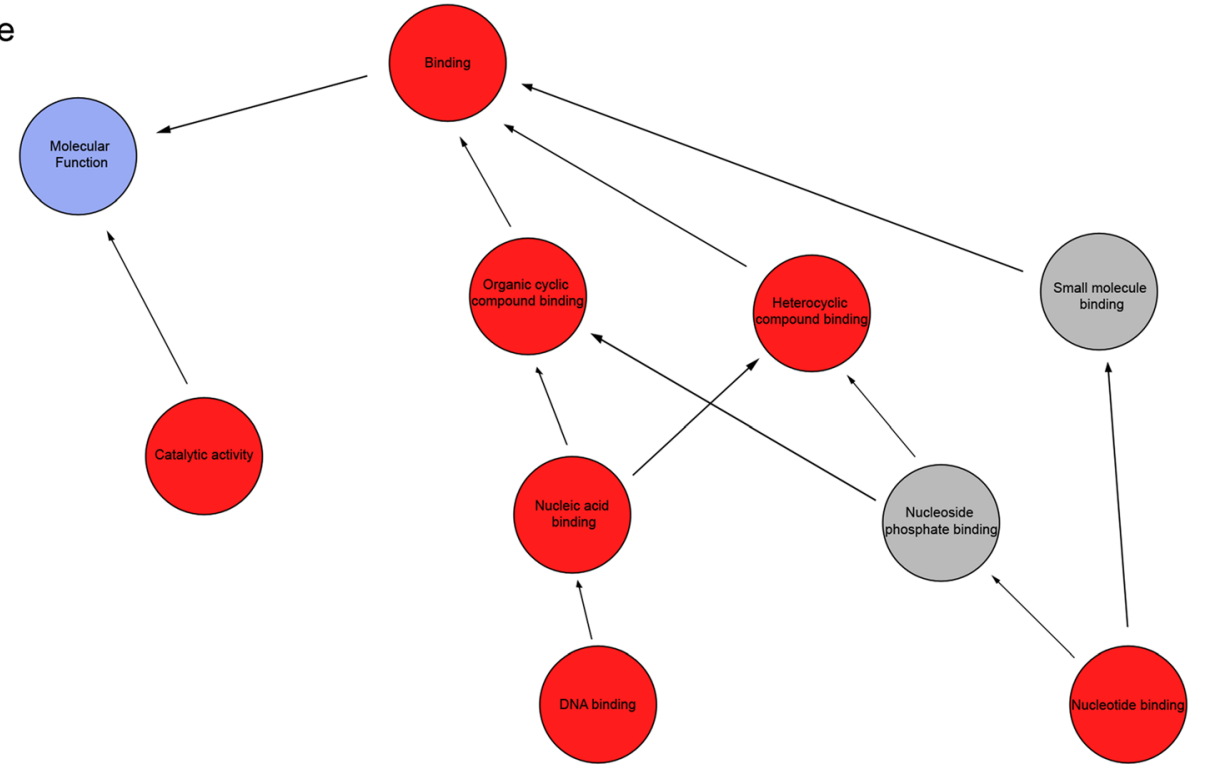

describing the presence of copies of protein-coding genes, rRNA genes, pseudogenes, and transcriptionally active sequences on Bs. Multigene families for rRNA (López-León et al. 1994; Donald et al. 1995; Stitou et al. 2000; van Vugt et al. 2005; Bidau et al. 2004; Silva and Yassuda 2004; Baroni et al. 2009; Poletto et al. 2010), H1, H3, and H4 histones (Teruel et al. 2010; Oliveira et al. 2011; Silva et al. 2014, 2016; Utsunomia et al. 2016) and U2 snRNA (Bueno et al. 2013) have also been observed in the $B$ chromosomes of many species. Indirect evidence of B activity was first described for the grasshopper Dichroplus pratensis (Bidau 1986) and the mosquito Simulium juxtacrenobium (Brockhouse et al. 1989) through the identification of nucleolar phenotypes related to rRNA gene expression. Indeed, the first molecular evidence of gene activity on B chromosomes was the finding of rRNA gene transcription in the plant Crepis capillaris (Leach et al. 2005) and in the parasitoid wasp Trichogramma kaykai (van Vugt et al. 2005). Transcription 
of B chromosome rRNA gene copies was later identified in the grasshopper Eyprepocnemis plorans (Ruiz-Estévez et al. 2013, 2014). The most recent findings regarding this subject provided evidence that various repetitive DNAs are transcriptionally modulated by B chromosomes (Lamb et al. 2007; Carchilan et al. 2007, 2009; Klemme et al. 2013; BanaeiMoghaddam et al. 2015; Ramos et al. 2016).

The proto-oncogene c-KIT maps to B chromosomes of the canids red fox and Chinese and Japanese raccoon dogs (Graphodatsky et al. 2005; Yudkin et al. 2007) and in the ruminant Siberian roe deer (Trifonov et al. 2013). This gene is transcriptionally active in the Siberian deer. Several genes involved in microtubule organization (TUBB1, TUBB5), kinetochore structure (SKA1, KIF11, CENP-E), recombination (XRCC2, SYCP2, RTEL1), and progression through the cell cycle (Separase, AURK) were identified in the B chromosomes of the cichlid fish A. latifasciata (Valente et al. 2014). Transcriptome analysis revealed that B-chromosomal copies of the Separase, TUBB1, and KIF11 genes are transcribed in another cichlid fish, Pundamilia niererei (Valente et al. 2014). RNAseq applied to transcriptome analyses of maize with varying copies of $\mathrm{B}$ chromosome $(\mathrm{B} 73+0 \mathrm{~B}, \mathrm{~B} 73+1 \mathrm{~B}$, and $\mathrm{B} 73+6 \mathrm{Bs})$ provides evidence that the expression of genes in the A genome is influenced by the presence of $\mathrm{B}$ chromosomes and that higher numbers of Bs generate more obvious phenotypic effects (Huang et al. 2016). Other authors have also demonstrated the effects of $\mathrm{B}$ chromosomes on the transcription of the A genome (Carchilan et al. 2009; Banaei-Moghaddam et al. 2013, 2015).

The presence of genes and functional sequences in Bs and their action over the whole genome modifies the conventional interpretation of B chromosomes as non-functional elements and suggests that $\mathrm{B}$ chromosomes can cause extensive changes over the whole transcriptional profile of cells with important implications for cell biology.

\section{B chromosomes in the context of integrative omics and biological networks}

Systems biology is another emergent area in biological science and analyzes biological phenomena from a holistic rather than a reductionist perspective. The integrative principle offered by systems biology is an important concept for biology because the analysis of complex systems in other areas has shown that the features of a system arise from the interaction of its components; thus, systems have emergent properties that cannot be observed when the components are investigated separately.

Although this emergent science remains new to most biologists, it has proved highly effective for the understanding of protein-protein interactions, regulatory and metabolic networks, and other biological interactions. Biological networks obey a power-law distribution concerning the degree (the number of edges for a node) of their nodes (the nodes can be genes, proteins, or enzymes, etc.), thus fitting the small world effect; thus, a few edges convey information among lots of nodes, as can be explained by the Barabási-Albert model. This model predicts (i) the high flexibility and integrity of biological networks (they are resistant to random perturbations); (ii) the growth in networks resulting from biological evolution; and (iii) the preferential attachment of new nodes (new nodes prefer to bind to older, highly connected nodes; the rich-getricher principle) (Barzel et al. 2012). Systems biology is currently well connected to omics sciences because the latter provides large-scale data (e.g., RNA-Seq can provide thousands of transcript expression measurements from which coexpression networks can be inferred).

Differential expression analyses of $\mathrm{B}+$ and $\mathrm{B}-$ total tissue messenger RNAs (mRNAs) of A. latifasciata have revealed genes that are involved with important cell structures/processes, such as the structural maintenance of cells and chromosomes, gene regulation, and the cell cycle (Marques et al. in preparation). The inference of coexpression networks (Spearman's rank correlation) (Ballouz et al. 2015) using RNA-Seq from the B+ and B - genotypes of A. latifasciata and computational analysis reveals that both nets fit the power-law distribution for degrees (Fig. 2a), indicating that the networks are nonrandom and possess the small-world property. The $\mathrm{B}+$ genotype network is larger than the $\mathrm{B}-$ network ( $>4 \mathrm{M}$ connections) and is also more diverse (Fig. 2b); furthermore, the degrees for all transcripts are significantly different ( $p$ value $\ll 0.001$ according to the Kruskal-Wallis test) between the networks. However, the $\mathrm{B}+$ and $\mathrm{B}-$ networks do not differ greatly in the number of transcripts (177,534 and 175,819 for the $\mathrm{B}-$ and $\mathrm{B}+$ networks, respectively) and have many nodes in common $(170,845)$ (Fig. 2c). Network comparative analysis indicates that B parasitism is not only related to the expression of its own genes but also modifies A genome expression; otherwise, the co-expression networks would not differ between the genotypes; this finding suggests that B exerts a high level of edge rewiring of the network.

All nodes of both networks were submitted to a gene ontology annotation (94,900 transcripts were annotated); 88,870 annotated transcripts are shared between the networks, and 3356 and 2674 transcripts are exclusive to Band $\mathrm{B}+$, respectively (Fig. 2c). A detailed analysis of the genes that are present in the most highly scored nodes for the molecular function domain (DNA binding and nucleotide binding terms) retrieved six genes that were exclusive to the B+ network annotation (Fig. 2e, Table 1). Most of these genes (LRC23 and RRP7A are the exceptions) 
Table 1 Gene ontology analysis of the genes present in the B+ network annotated as high-scored nodes for the molecular function domain

\begin{tabular}{|c|c|c|c|}
\hline Gene ID & Gene name & $\begin{array}{l}\text { GO molecular } \\
\text { function }\end{array}$ & Function \\
\hline LRC23 & $\begin{array}{l}\text { Leucine-rich } \\
\text { repeat- } \\
\text { containing pro- } \\
\text { tein } 23\end{array}$ & - & - \\
\hline PPRC1 & $\begin{array}{l}\text { Peroxisome } \\
\text { proliferator- } \\
\text { activated recep- } \\
\text { tor gamma } \\
\text { coactivator- } \\
\text { related protein } 1\end{array}$ & $\begin{array}{l}\text { Regulation of } \\
\text { transcription } \\
\text { DNA-templated; } \\
\text { mitochondrion } \\
\text { organization }\end{array}$ & $\begin{array}{l}\text { Acts as a } \\
\text { coactivator } \\
\text { during the } \\
\text { transcriptional } \\
\text { activation of } \\
\text { nuclear genes } \\
\text { related to } \\
\text { mitochondrial } \\
\text { biogenesis and } \\
\text { cell growth }\end{array}$ \\
\hline RRP7A & $\begin{array}{l}\text { Ribosomal RNA- } \\
\text { processing pro- } \\
\text { tein } 7 \text { homolog } \\
\text { A }\end{array}$ & $\begin{array}{l}\text { Ribosomal small } \\
\text { subunit } \\
\text { assembly; } \\
\text { blastocyst } \\
\text { formation; } \\
\text { rRNA } \\
\text { processing }\end{array}$ & - \\
\hline MSGN1 & Mesogenin-1 & $\begin{array}{l}\text { Regulation of } \\
\text { transcription } \\
\text { DNA-templated; } \\
\text { somitogenesis }\end{array}$ & $\begin{array}{l}\text { May regulate the } \\
\text { expression of T- } \\
\text { box transcription } \\
\text { factors required } \\
\text { for mesoderm } \\
\text { formation and } \\
\text { differentiation }\end{array}$ \\
\hline MYCBP & $\begin{array}{l}\text { C-Myc-binding } \\
\text { protein }\end{array}$ & $\begin{array}{l}\text { Regulation of } \\
\text { transcription } \\
\text { DNA-templated; } \\
\text { protein } \\
\text { ubiquitination }\end{array}$ & $\begin{array}{l}\text { May control the } \\
\text { transcriptional } \\
\text { activity of MYC }\end{array}$ \\
\hline NR2F6 & $\begin{array}{l}\text { Nuclear receptor } \\
\text { subfamily } 2 \\
\text { group F } \\
\text { member } 6\end{array}$ & $\begin{array}{l}\text { Regulation of } \\
\text { transcription } \\
\text { DNA-templated; } \\
\text { neuron develop- } \\
\text { ment; steroid } \\
\text { hormone- } \\
\text { mediated signal- } \\
\text { ing pathway }\end{array}$ & $\begin{array}{l}\text { Transcription factor } \\
\text { predominantly } \\
\text { involved in } \\
\text { transcriptional } \\
\text { repression. } \\
\text { Involved in the } \\
\text { modulation of } \\
\text { hormonal } \\
\text { responses }\end{array}$ \\
\hline ZNF596 & $\begin{array}{l}\text { Zinc finger protein } \\
596\end{array}$ & $\begin{array}{l}\text { Regulation of } \\
\text { transcription } \\
\text { DNA-template }\end{array}$ & - \\
\hline
\end{tabular}

encode proteins that regulate gene transcription. For instance, in humans, MYCBP binds to MYC after its expression is increased, generating positive feedback (Taira et al. 1998; Furusawa et al. 2001). MYC in eukaryotes is a transcription factor that regulates the cell cycle and cell differentiation (McMahon et al. 1998) and also plays a role in preventing chromosomal rearrangements through the induction of telomerase activity ( $\mathrm{Wu}$ et al. 1999). Transcription factors were also found in our analysis
(NR2F6 and MSGN1), and ZNF596 was the only transcription factor that was found with high integrity levels in the B gene list reported by Valente et al. (2014) ( $71 \%$ for XM 004572867.1 and XM 004574919.1 and $\sim 63.4 \%$ for XM 004576325.1).

Similar data were obtained during the micro-RNA (miRNA) analysis of whole microRNomes of $\mathrm{B}+$ tissues compared to B- tissues of A. latifasciata (Fantinatti et al. in preparation) (Fig. 2d); these data highlight the fact that miRNAs are involved in processes that are related to cell development and cell cycle control, cellular division, and other functions. Based on such an integrative analysis, it was also clearly observed that the effects of B chromosomes on the host genome are extraordinarily variable depending on the tissue analyzed; this suggests that $\mathrm{B}$ chromosome activity is somewhat dependent on the environmental condition of cells. For example, among the target genes of differentially expressed $\mathrm{B}+$ miRNAs, it can be observed through target prediction that the Neurog1 gene is targeted by three female-specific, up-regulated miRNAs (Fig. 2d). It is known that in zebrafish, Neurog1 is involved in the regulation of cell fate during neuronal tissue development (Onoguchi et al. 2012) and is also involved in ganglion development (Andermann et al. 2002).

Although it is not clear how Bs exert their influence on cell biology, we hypothesize that regulators expressed by Bs, such as transcription factors, miRNAs, and other ncRNAs (including lncRNAs) might trigger extensive Agenome expression changes. Noncoding RNA represents one of the most expressed RNA classes in the cell and has been highly explored in recent years because of their importance in controlling several biological processes (Morris and Mattick 2014; Rinn and Guttman 2014). Based on the accumulated evidence obtained from several organisms, we propose that B chromosomes might modulate cell biology through (i) the production of regulatory RNAs that are transcribed from B sequences and/or (ii) the differential expression of B paralog genes. Indeed, we know that the $\mathrm{B}$ chromosome of A. latifasciata regulates the expression of noncoding RNAs, thus influencing Agenome expression (Ramos et al. 2016; Fantinatti et al. in preparation; Marques et al. in preparation), as is observed in other species (Carchilan et al. 2009; Akbari et al. 2013; Banaei-Moghaddam et al. 2013, 2015; Huang et al. 2016). Some individuals of the Nasonia vitripennis genome contain a supernumerary (B) chromosome known as paternal sex ratio (PSR) that expresses both potentially coding and noncoding transcripts that could act over the B transmission to males (Akbari et al. 2013). Furthermore, in vitro activity of a $\mathrm{B}$ chromosome encoded protein gene (Argonaute-like, involved in the regulation of gene expression) was for the first time observed in rye, 
providing evidences that a $\mathrm{B}$ derived protein could act silencing chromatin/DNA elements (Ma et al. 2016). We propose that the expression of regulators from Bs could initiate a cascade of events, apparently in a selfish strategy, thus altering the expression of A-genes in a nonBoolean way for pre- and post-transcriptional regulation as well as translational regulation. Our co-expression network analysis for A. latifasciata strongly supports the notion that the influence of $\mathrm{B}$ on the A complement is not slight but that it widely changes cell physiology. Currently, we can state that Bs are probably maintained in the cell and transmitted between generations by this mechanism.

\section{Final remarks}

The accumulated data suggests that B can act by manipulating the entire cell system to benefit its own survival. However, the mechanism by which this is accomplished remains completely unknown. We can hypothesize that B acts in a manner similar to the parasitic dodder plant, which seems to continuously track the physiological status of the host and uses its own mRNA to manipulate the host in a manner that benefits the parasite (Kim et al. 2014). We suggest that the next steps in B chromosome science are to determine whether the A-genome control that results from the presence of B is "motivated" by a parasitic behavior similar to that exhibited by dodder. A complementary focus would use strategies involving extensive networks analysis, such as that illustrated here, to better understand the parasitism strategy used by Bs from a systemic perspective. Omics, computational science, and systems biology are the most suitable strategies to answer questions such as the following: (i) Does the B chromosome "monitor" Agenome expression to influence systemic changes for its own benefit? (ii) How does the signaling cascade of co-expression and protein-protein interactions alter A-genome expression? (iii) Could B chromosomes influence other important networks in the cell that are unrelated to its parasitism?

Acknowledgment This work was supported by grants from São Paulo Research Foundation (13/04533-3), the National Council for Scientific and Technological Development (474684/2013-0, 301728/2011-9), and São Paulo State University (0045/021/13-PROPe/CDC).

\section{Compliance with ethical standards}

Conflict of interest The authors declare that they have no competing interests.

Ethics approval and consent to participate All applicable international, national, and/or institutional guidelines for the care and use of animals were followed.

This article does not contain any studies with human participants performed by any of the authors.
Funding This work was supported by grants from São Paulo Research Foundation (13/04533-3), the National Council for Scientific and Technological Development (474684/2013-0, 301728/2011-9), and São Paulo State University (0045/021/13-PROPe/CDC).

\section{References}

Akbari OS, Antoshechkin I, Hay BA, Ferree PM (2013) Transcriptome profiling of Nasonia vitripennis testis reveals novel transcripts expressed from the selfish B chromosome, paternal sex ratio. G3 3: $1597-1605$

Andermann P, Ungos J, Raible DW (2002) Neurogenin1 defines zebrafish cranial sensory ganglia precursors. Dev Biol 251:45-58

Ballouz S, Verleyen W, Gillis J (2015) Guidance for RNA-seq co-expression network construction and analysis: safety in numbers. Bioinformatics 31:2123-2130

Banaei-Moghaddam AM, Meier K, Karimi-Ashtiyani R, Houben A (2013) Formation and expression of pseudogenes on the B chromosome of rye. Plant Cell 25:2536-2544

Banaei-Moghaddam AM, Martis MM, Macas J, Gundlach H, Himmelbach A, Altschmied L, Mayer KFX, Houben A (2015) Genes on B chromosomes: old questions revisited with new tools. Biochim Biophys Acta 1849:64-70

Baroni S, Lopes CE, Almeida-Toledo LF (2009) Cytogenetic characterization of Metynnis maculatus (Teleostei; Characiformes): the description in Serrasalminae of a small B chromosome bearing inactive NOR-like sequences. Caryologia 62:95-101

Barzel B, Sharma A, Bababási A-L (2012) Graph theory properties of cellular networks. In: Walhout M, Vidal M, Dekker J (eds) Handbook of systems biology: concepts and insights, 1st edn. Academic Press, Cambridge, pp. 177-193

Bidau CJ (1986) A nucleolar-organizing B chromosome showing segregation-distortion in the grasshopper Dichroplus pratensis (Melanoplinae, Acrididae. Can J Genet Cytol 28:138-148

Bidau CJ, Rosato M, Martí DA (2004) FISH detection of ribosomal cistrons and assortment-distortion for $\mathrm{X}$ and $\mathrm{B}$ chromosomes in Dichroplus pratensis (Acrididae. Cytogenet Genome Res 106: 295-301

Brockhouse C, Bas JAB, Fereday RM, Strauss NA (1989) Supernumerary chromosomes evolution in the Simulium vernum group (Diptera: Simulidae. Genome 32:516-521

Bueno D, Palacios-Gimenez OM, Cabral-de-Mello DC (2013) Chromosomal mapping of repetitive DNAs in Abracris flavolineata reveal possible ancestry for the B chromosome and surprisingly $\mathrm{H} 3$ histone spreading. PLoS One 8:e66532

Burt A, Trivers R (2006) Genes in conflict: the biology of selfish genetic elements. Belknap Press of Harvard University, Cambridge

Camacho JPM (2005) B chromosomes. In: Gregory TR (ed) The evolution of the genome, 1st edn. Elsevier, San Diego, pp. 223-286

Camacho JP, Sharbel TF, Beukeboom LW (2000) B-chromosome evolution. Philos T Roy Soc B 355:163-178

Carchilan M, Delgado M, Ribeiro T, Costa-Nunes P, Caperta A, MoraisCecilio L, Jones RN, Viegas W, Houben A (2007) Transcriptionally active heterochromatin in rye B chromosomes. Plant Cell 19:17381749

Carchilan M, Kumke K, Mikolajewski S, Houben A (2009) Rye B chromosomes are weakly transcribed and might alter the transcriptional activity of a chromosome sequences. Chromosoma 118:607-616

Coleman JJ, Rounsley SD, Rodriguez-Carres M, Kuo A, et al. (2009) The genome of Nectria haematococca: contribution of supernumerary chromosomes to gene expansion. PLoS Genet 5:e1000618

Donald TM, Leach CR, Clough A, Timmis JN (1995) Ribosomal RNA genes and the $\mathrm{B}$ chromosome of Brachycome dichromosomatica. Heredity 74:556-561 
Furusawa M, Ohnishi T, Taira T, Iguchi-Ariga SM, Ariga HJ (2001) AMY-1, a c-Myc-binding protein, is localized in the mitochondria of sperm by association with S-AKAP84, an anchor protein of cAMP-dependent protein kinase. Biol Chem 276:36647-36651

Gall JG, Pardue ML (1969) Formation and detection of RNA-DNA hybrid molecules in cytological preparations. Proc Natl Acad Sci U S A $63: 378-383$

Goodwin SB, M'barek SB, Dhillon B, Wittenberg AHJ, Crane CF, et al. (2011) Finished genome of the fungal wheat pathogen Mycosphaerella graminicola reveals dispensome structure, chromosome plasticity, and stealth pathogenesis. PLoS Genet 7:e1002070

Graphodatsky AS, Kukekova AV, Yudkin DV, Trifonov VA, Vorobieva NV, Beklemisheva VR, et al. (2005) The proto-oncogene c-KIT maps to canid B-chromosomes. Chromosom Res 13:113-122

Huang W, Du Y, Zhao X, Jin W (2016) B chromosome contains active genes and impacts the transcription of a chromosomes in maize (Zea mays L.). BMC Plant Biol 16:88

Jones RN (1991) B-chromosome drive. Am Nat 137:430-442

Jones RN (1995) B chromosomes in plants. New Phytol 131:411-434

Jones RN, Rees H (1982) B chromosomes. Academic Press, London

Kim G, LeBlanc ML, Wafula EK, dePamphilis CW, Westwood JH (2014) Genomic-scale exchange of mRNA between a parasitic plant and its hosts. Science 345:808-811

Klemme S, Banaei-Moghaddam AM, Macas J, Wicker T, Novak P, Houben A (2013) High-copy sequences reveal distinct evolution of the rye B chromosome. New Phytol 199:550-558

Lamb JC, Riddle NC, Cheng YM, Theuri J, Birchler JA (2007) Localization and transcription of a retrotransposon-derived element on the maize B chromosome. Chromosom Res 15:383-398

Leach CR, Houben A, Bruce F, Pistrick K, Demidov D, et al. (2005) Molecular evidence for transcription of genes on a B chromosome in Crepis capillaris. Genetics 171:269-278

López-León M, Neves N, Schwarzacher T, Heslop-Harrison J, Hewitt G, Camacho J (1994) Possible origin of a B chromosome deduced from its DNA composition using double FISH technique. Chromosom Res 2:87-92

Ma W, Gabriel TS, Martis MM, Gursinsky T, Schubert V, Vrána J, Doležel J, Grundlach H, Altschmied L, Scholz U, Himmelbach A, Behrens SE, Banaei-Moghaddam AM, Houben A (2016) Rye B chromosomes encode a functional Argonaute-like protein with in vitro slicer activities similar to it's a chromosome paralog. New Phytol doi. doi:10.1111/nph.14110

Martins C, Cabral-de-Mello DC, Valente GT, Mazzuchelli J, Oliveira SG, Pinhal D (2011) Animal genomes under the focus of cytogenetics. Nova Science Publisher, Hauppauge

Martis MM, Klemme S, Banaei-Moghaddam AM, Blattner FR, Macas J, Schmutzer T, et al. (2012) Selfish supernumerary chromosome reveals its origin as a mosaic of host genome and organellar sequences. Proc Nat Ac Sci USA 109:13343-13346

McMahon SB, Van Buskirk HA, Dugan KA, Copeland TD, Cole MD (1998) The novel ATM-related protein TRRAP is an essential cofactor for the c-Myc and E2F oncoproteins. Cell 94:363-374

Miao VP, Covert SF, Van Etten HD (1991) A fungal gene for antibiotic resistance on a dispensable ("B") chromosome. Science 254:1773-1776

Morris KV, Mattick JS (2014) The rise of regulatory RNA. Nat Rev Genet $15: 423-437$

Oliveira NL, Cabral-de-Mello DC, Rocha MF, Loreto V, Martins C, Moura RC (2011) Chromosomal mapping of rDNAs and H3 histone sequences in the grasshopper Rhammatocerus brasiliensis (Acrididae, Gomphocerinae): extensive chromosomal dispersion and co-localization of $5 \mathrm{~S} \mathrm{rDNA} / \mathrm{H} 3$ histone clusters in the A complement and B chromosome. Mol Cytogenet 4:24
Onoguchi M, Hirabayashi Y, Koseki H, Gotoh Y (2012) A noncoding RNA regulates the neurogenin 1 gene locus during mouse neocortical development. Proc Nat Ac Sci USA 109:16939-16944

Pardue ML, Gall JG (1969) Molecular hybridization of radioactive DNA to the DNA of cytological preparations. Proc Natl Acad Sci U S A 64:600-604

Pinkel D, Straume T, Gray JW (1986) Cytogenetic analysis using quantitative, high-sensitivity, fluorescence hybridization. Proc Natl Acad Sci U S A 83:2934-2938

Poletto AB, Ferreira IA, Martins C (2010) The B chromosomes of the African cichlid fish Haplochromis obliquidens harbour 18S rRNA gene copies. BMC Genet 11:1

Ramos E, Cardoso AL, Brown J, Marques DF, Fantinatti BEA, Cabralde-Mello DC, Oliveira RA, O'Neill RJ, Martins C (2016) The repetitive DNA element BncDNA, enriched in the B chromosome of the cichlid fish Astatotilapia latifasciata, transcribes a potentially noncoding RNA. Chromosoma (in press)

Rinn J, Guttman M (2014) RNA and dynamic nuclear organization. Science 345:1240-1241

Ruì-Estévez M, López-León MD, Cabrero J, Camacho JP (2013) Ribosomal DNA is active in different B chromosome variants of the grasshopper Eyprepocnemis plorans. Genetica 141:337-345

Ruìz-Estévez M, Badisco L, Broeck JV, Perfectti F, Lopez-Leon MD, Cabrero J, Camacho JP (2014) B chromosomes showing active ribosomal RNA genes contribute insignificant amounts of rRNA in the grasshopper Eyprepocnemis plorans. Mol Gen Genomics 289: $1209-1216$

Silva MJJ, Yonenaga-Yassuda Y (2004) B chromosomes in Brazilian rodents. Cytogenet Genome Res 106:257-263

Silva DMZA, Pansonato-Alves JC, Utsunomia R, Araya-Jaime C, RuizRuano FJ, et al. (2014) Delimiting the origin of a B chromosome by fish mapping, chromosome painting and DNA sequence analysis in Astyanax paranae (Teleostei, Characiformes. PLoS One 9:e94896

Silva DMZA, Daniel SN, Camacho JP, Utsunomia R, Ruiz-Ruano FJ, Penitente M, Pansonato-Alves JC, Hashimoto DT, Oliveira C, Porto-Foresti F, Foresti F (2016) Origin of B chromosomes in the genus Astyanax (Characiformes, Characidae) and the limits of chromosome painting. Mol Gen Genomics 291:1407-1418

Stitou S, de la Guardia D, Jiménez R, Burgos M (2000) Inactive ribosomal cistrons are spread throughout the $\mathrm{B}$ chromosomes of Rattus rattus (Rodentia, Muridae). Implications for their origin and evolution. Chromosom Res 8:305-311

Taira T, Maëda J, Onishi T, Kitaura H, Yoshida S, Kato H, Ikeda M, Tamai K, Iguchi-Ariga SM, Ariga H (1998) AMY-1, a novel CMYC binding protein that stimulates transcription activity of $\mathrm{C}$ MYC. Genes Cells 3:549-565

Teruel M, Cabrero J, Perfectti F, Camacho JPM (2010) B chromosome ancestry revealed by histone genes in the migratory locust. Chromosoma 119:217-225

Trifonov VA, Dementyeva PV, Larkin DM, O'Brien PC, Perelman PL, Yang F, et al. (2013) Transcription of a protein-coding gene on B chromosomes of the Siberian roe deer (Capreolus pygargus. BMC Biol 11:90

Utsunomia R, Silva DMZA, Ruiz-Ruano FJ, Araya-Jaime C, PansonatoAlves JC, Scacchetti PC, et al. (2016) Uncovering the ancestry of B chromosomes in Moenkhausia sanctaefilomenae (Teleostei, Characidae). PLoS One 11:e0150573

Valente GT, Conte MA, Fantinatti BEA, Cabral-de-Mello DC, Carvalho RF, Vicari MR, Kocher TD, Martins C (2014) Origin and evolution of $\mathrm{B}$ chromosomes in the cichlid fish Astatotilapia latifasciata based on integrated genomic analyses. Mol Biol Evol 31:2061-2072

van Vugt JJFA, de Nooijer S, Stouthamer R, de Jong H (2005) NOR activity and repeat sequences of the paternal sex ratio chromosome of the parasitoid wasp Trichogramma kaykai. Chromosoma 114: $410-419$ 
Wilson EB (1907) The supernumerary chromosomes of Hemiptera. Science 26:870-871

Wittenberg AHJ, van der Lee TAJ, Ben M'Barek S, Ware SB, Goodwin SB, et al. (2009) Meiosis drives extraordinary genome plasticity in the haploid fungal plant pathogen Mycosphaerella graminicola. PLoS One 4:e5863

Wu KJ, Grandori C, Amacker M, Simon-Vermot N, Polack A, Lingner J, Dalla-Favera R (1999) Direct activation of TERT transcription by cMYC. Nat Genet 21:220-224
Yoshida K, Terai Y, Mizoiri S, Aibara M, Nishihara H, Watanabe M, et al. (2011) B chromosomes have a functional effect on female sex determination in Lake Victoria cichlid fishes. PLoS Genet 7:e1002203

Yudkin DV, Trifonov VA, Kukekova AV, Vorobieva NV, Rubtsova NV, Yang F, et al. (2007) Mapping of KIT adjacent sequences on canid autosomes and B chromosomes. Cytogenet Genome Res 116:100 103 